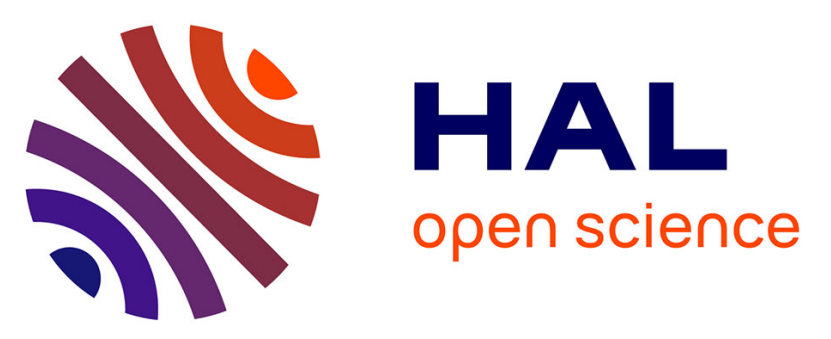

\title{
Testing the consistency between goals and policies for sustainable development: mental models of how the world works today are inconsistent with mental models of how the world will work in the future

\author{
C. Richert, F. Boschetti, I. Walker, J. Price, N. Grigg
}

\section{To cite this version:}

C. Richert, F. Boschetti, I. Walker, J. Price, N. Grigg. Testing the consistency between goals and policies for sustainable development: mental models of how the world works today are inconsistent with mental models of how the world will work in the future. Sustainability Science, 2017, 12 (1), pp.45-64. 10.1007/s11625-016-0384-2 . hal-01739553

\section{HAL Id: hal-01739553 \\ https://hal.science/hal-01739553}

Submitted on 21 Mar 2018

HAL is a multi-disciplinary open access archive for the deposit and dissemination of scientific research documents, whether they are published or not. The documents may come from teaching and research institutions in France or abroad, or from public or private research centers.
L'archive ouverte pluridisciplinaire HAL, est destinée au dépôt et à la diffusion de documents scientifiques de niveau recherche, publiés ou non, émanant des établissements d'enseignement et de recherche français ou étrangers, des laboratoires publics ou privés. 
Testing the consistency between goals and policies for sustainable development: Mental models of how the world works today are inconsistent with mental models of how the world will work in the future

Claire Richert $^{1 *}$, Fabio Boschetti ${ }^{2,3}$, Iain Walker ${ }^{2,4}$, Jennifer Price $^{2}$ and Nicola Grigg ${ }^{2}$

\section{Affiliations}

${ }^{1}$ IRSTEA UMR G-EAU, France.

${ }^{2}$ Commonwealth Scientific and Industrial Organisation, Australia.

${ }^{3}$ School of Earth and Geographical Sciences, The University of Western Australia

${ }^{4}$ School of Psychology, The University of Western Australia

\section{Corresponding author:}

E-mail address: claire.richert@irstea.fr

Telephone number: +33607491947

Present address: 361 rue Jean-François Breton, 34196 Montpellier, France 


\begin{abstract}
Understanding complex problems such as climate change is difficult for most non-scientists, with serious implications for decision-making and policy support. Scientists generate complex computational models of climate systems to describe and understand those systems and to predict the future states of the systems. Non-scientists generate mental models of climate systems, perhaps with the same aims and perhaps with other aims too. Often, the predictions of computational models and of mental models do not correspond, with important implications for human decision-making, policy support, and behaviour change. Recent research has suggested non-scientists' poor appreciation of the simple foundations of system dynamics is at the root of the lack of correspondence between computational and mental models. We report here a study that uses a simple computational model to 'run' mental models to assess whether a system will evolve according to our aspirations when considering policy choices. We provide novel evidence of a dual process model: how we believe the system works today is a function of ideology and worldviews; how we believe the system will look in the future is related to other, more general, expectations about the future. The mismatch between these different aspects of cognition may prevent establishing a coherent link between a mental model's assumptions and consequences, between the present and the future, thus potentially limiting decision-making, policy support, and other behaviour changes.
\end{abstract}

Keywords: mental models; climate change; beliefs about the future 


\section{Introduction}

\section{Important definitions used in this article:}

Formal model: a formal model contains variables connected to each other by mathematically specified relationships.

Computational model: some formal models do not have analytical solutions. In that case, their behavior can be studied by using computer simulation. These kinds of models are called "computational models". In order to study the behavior of a computational model, it needs to be executed (or "run"), that is to say that its outputs need to be calculated given specific inputs.

Mental model: mental models are "personal, internal representations of external reality that people use to interact with the world around them [...They] are used to reason and make decisions and can be the basis of individual behaviors" (Jones, Ross et al. 2011).

Value: "Values (1) are concepts or beliefs, (2) pertain to desirable end states or behaviors, (3) transcend specific situations, (4) guide selection or evaluation of behavior and events, and (5) are ordered by relative importance." (Schwartz 1992)

Attitude: an attitude is "a psychological tendency that is expressed by evaluating a particular entity with some degree of favor or disfavor." (Eagly and Chaiken 1993)

Cognitive signature: a cognitive signature is the set of attitudes, worldviews, and ideological beliefs which characterise an individual and affect the way she or he frames and understands a decision-making problem.

Environmental systems, social systems, and economic systems alike are challenged by global climate change. Human activity is a primary driver of climate change, and must also be central to mitigation and adaptation efforts. How people understand environmental, social, and economic systems, independently and interdependently, is critical for policy support and behaviour change.

In discussing decision making and policy support for sustainable development, Wiek and Iwaniec (2014) suggest that society needs a shared vision of a desirable future and Wiek, Withycombe et al. (2011) consider system thinking and anticipatory thinking as two core competencies needed to achieve sustainable change. Here system thinking refers to the ability to analyse how socio-ecological systems function and anticipatory thinking refers to the ability to imagine what scenario a socio-ecological system may need to follow in order to achieve the shared vision. Implicit in this view is the assumption that if a shared vision is not achieved the problem is 
likely to reside either in the system thinking (the system functioning was not properly understood), the anticipatory thinking (hurdles or constraints in the vision were not fully appreciated) or the implementation (failures prevented the chosen strategy to be realised). Naturally, system thinking, anticipatory thinking and implementation are all error prone and entire fields of research are devoted to improve these processes. For example, computer models and expert training can refine system thinking and acquiring better understanding of people's mental models about climate change and other sustainability issues could improve anticipatory thinking and implementation by identifying generally held misconceptions, realign communication strategies accordingly, and frame and design policies that are more in line with people's expectations.

System thinking, anticipatory thinking and implementation issues are often treated separately and consistency between these three processes is assumed a priori. For example, in the fields of information theory and complex system science, system thinking and anticipatory thinking are taken to be the same process (Crutchfield 1994, Shalizi and Crutchfield 2001, Hohwy 2013) since the system understanding is assumed to also generate the anticipation and guide the implementation. In the field of human decision making, this is not necessarily the case. Visions, understanding and strategies are often provided by different individuals and generated via different processes (academic vs participatory, for example). Indeed, as mentioned above, in relation to sustainable development Wiek, Withycombe et al. (2011) consider system thinking and anticipatory thinking as two distinct competencies. According to this view, system thinking relates to technical analytical skills (comprehending, empirically verifying, and articulating) while anticipatory competency also requires crafting narratives and imagery. It is thus reasonable to question whether consistency between system thinking, anticipatory thinking and implementation should be assumed a priori in human decision making.

In this work we address this question empirically within the context of policy support for climate change mitigation. Via an online survey we explore system thinking (how the interaction 
Author-produced version of the article published in Sustainability Science, 2017, N ${ }^{\circ} 12(1)$, p. 45-64.

between warming, economic growth and population growth works), implementation preferences (mitigation policy choices) and anticipatory thinking (expected future global warming and economic growth) for members of the general public. In addition, we assess the cognitive signature of the responders and we use a computer model to simulate the impact of the responders' policy choices on the chosen system. This experimental design allows us to explore the consistency between system thinking, anticipatory thinking and implementation and to show that ensuring consistency is paramount for sustainable development.

The paper is organised in the following way: in section 2, we review the current understanding of mental models and its relevance to sustainable development; in section 3 , we present the approach we followed to explore the consistency between system thinking, anticipatory thinking, and implementation; in section 4, we describe the material and methods used in our study; in section 5, we present the results; finally, we discuss the results and conclude in section 6.

\section{Mental models: current understanding and challenges for sustainability}

What is a mental model? There is a vast literature on mental models from many disciplines (Jones, Ross et al. 2011), (Johnson-Laird 2013). In general, this literature agrees that mental models are simplified representations of reality, may or may not be logically or dynamically consistent, can change in time, and that their existence or features may or may not be consciously accessible (Norman 1987, Greca and Moreira 2000, Jones, Ross et al. 2011). However, there is little agreement on the content of mental models (dynamical components vs images or attitudes), their mode of functioning (computational vs analogical vs emotional; static vs dynamic) and their role or purpose (prediction vs system justification). Definitions range from a computational device on one hand (Johnson-Laird, Khemlani et al. 2015), to a collection of images and analogies partly inaccessible to direct elicitation on the other (Inayatullah 2004). 
When we study the possible role of mental models in policy support for climate change or other environmental sustainability initiatives, one main question arises: does the content of mental models include analogues of bio-physical variables, human behaviour, and causal relations? That is, are mental models 'a small-scale model of how the world works' (Craik 1943, Johnson-Laird 1983, Nowak, Rychwalska et al.2013), or are they composites of values and attitudes in a social psychology sense (Inayatullah 2004, Quinn 2005, Price, Walker et al. 2014)? In the first case, which we refer to as a 'system dynamic' view, a mental model may include, say, $\mathrm{CO}_{2}$ emissions, economic activities, sequestration processes, and mitigation initiatives and explicit assumptions about how they interact. The system dynamic view of a mental model is closely related to the system thinking competency described by Wiek, Withycombe et al. (2011). In the second case, which we refer to as an 'attitudinal' view, a mental model may include, say, aspirations, fears, and attitudes toward the environment, toward economic growth, and toward future generations. The attitudinal view of a mental model is related to the anticipatory competency described by Wiek, Withycombe et al. (2011) since it includes the tools through which people can value the potential scenarios the system may follow.

Current understanding makes answering the question above ('what does a mental model consist of?') difficult. It is likely that in actual mental models the system dynamics and the attitudinal components coexist and may even overlap and interfere. Which one dominates may depend on a mixture of factors, including cognitive abilities, domain knowledge, and cognitive effort, as well as problem context and affective significance. For example, a climate change mental model might be framed as an environmental, economic, social, or ethical issue, or as a combination of the four. Each of these frames may elicit a different system dynamic interpretation. Alternatively, insights gained from system understanding may lead an individual to place emphasis on a specific interpretation of the problem. Clarity in these relations is lacking, at least partly because eliciting mental models is difficult (Jones, Ross et al. 2011). 
The distinction between the dynamical and attitudinal view is important for several reasons. First, it affects the way we perceive the relation between past, present, and future states of the system. The 'system dynamic' view of mental models imposes clear dynamical constraints on a system's evolution. This evolution does not need to be deterministic, but needs to be dynamically consistent. The 'attitudinal' view of mental models does not impose such constraints and in fact allows attitudes toward the past, present, and future to have different cognitive roots (Boyd and Zimbardo 1997, Zimbardo and Boyd 1999) and to serve different functions (D'Argembeau and Van der Linden 2007, Suddendorf and Corballis 2007, D'Argembeau, Lardi et al. 2012), thus potentially allowing them to be inconsistent with one another. Second, in order to increase support for specific policies, the system dynamic view of mental models suggests that interventions should target system understanding (what is inside and outside the system and how the system functions (Stern and Raimi 2015)), while the attitudinal view of mental models suggests interventions should target values as well as the framing of policies in terms of the values we want to elicit (Bain, $\underline{\text { Hornsey et }}$ al. 2012).

This discussion is particularly relevant to intergenerational problems, like climate change. By their nature, intergenerational problems force us to contrapose the world as we understand it today to the world as it may look in a distant future. From a system dynamic perspective, these correspond to two potentially very different system states. A crucial question is whether these two states are perceived as static and unrelated or whether the transition between them is accounted for. From a system dynamic perspective, the latter requires 'running' the mental models, something which, unfortunately, people are poor at (Dorner 1996, Moxnes 1998, Moxnes 2000, Sweeney and Sterman 2000, Halford, Baker et al. 2005, Halford, Cowan et al. 2007, Cronin, Gonzalez et al. 2009, Moxnes and Saysel 2009). For climate change, many people misjudge the consequences of specific climate policies because of misunderstandings of the relation between $\mathrm{CO}_{2}$ emissions, sequestration, and accumulation, even when these relations are explicitly presented to them (Sterman 2008). 
From an attitudinal perspective, our images of today and of the close future (at which time policy choices affect the ones who make or support the choices) and of the distant future (when policy choices will affect future generations) have different cognitive features and roles. The distant future is the domain of high-level goals while the near future is the domain of concrete plans for action (Liberman and Trope 1998, Trope and Liberman 2003, Spreng and Levine 2006, Stawarczyk, Cassol et al. 2013). It follows that the far future has a role which is distinct from planning or conceiving practical goals or practical policies, focusing more on abstract representations (D'Argembeau, Renaud et al. 2011, D'Argembeau 2012). In principle, intergenerational problems force us to cross this cognitive gap, but we are left to wonder to what extent people are capable of doing so and of doing so meaningfully.

\section{Approach used to assess the consistency of mental models of climate change}

Clearly, addressing the gap between the present and close future, on the one hand, and the distant future on the other is challenging from both a system dynamic and an attitudinal perspective. The purpose of this study is to gain some insights on this challenge and to better understand the nature of the public's mental models related to the climate change debate, in terms of both system dynamics and attitudinal orientation. Within the limitations of our experimental setting, we aim to account for both a system dynamic and an attitudinal view of mental models by trying to elicit an approximate representation of both. With specific reference to the general public's view of the climate change debate, we ask whether there is consistency between the description of the system as it works today and the prediction of how the system may look in 2100 , as a function of specific policy preferences and other assumptions.

Consistency is the keyword here, and we distinguish between three different types of consistency. When considering attitudes, we refer to cognitive consistency as consistency between the attitudes reflecting or motivating the understanding of how the system works today and our policy choices on the one hand, and the attitudes reflecting or motivating the expectations of how 
the system may look in the future as a result of such choices on the other hand. To assess this, we measure a number of psychological constructs and study their inter-relationships and their relationships with policy preference. When considering system dynamics, we refer to dynamical consistency, that is, the extent to which a respondent's prediction of a system future state is compatible with his/her understanding of how the system works today and his/her policy choices. To assess the latter we use a numerical representation of a subjective dynamical mental model and compare respondents' predictions with the output of their numerical representation. Finally, we assess the relational consistency between the attitudinal and the system dynamic view of mental models. We do this by examining the relationships between an individual's set of attitudes and policy choices and his/her description of the world as it works today as specified by their preferences in a system dynamic model. The three types of consistency are summarized in Figure 1.

In order to check these different types of consistency, this study employs three components: i) a method to elicit an individual's attitudes and climate change beliefs ${ }^{1}$, ii) a method to elicit an individual's mental model of the interrelationships between population, climate change and economic impacts, and allow the individual to predict the outcomes of their own assumptions, and iii) a computational model which implements the individual mental models. We do this via an online survey designed to elicit respondents' attitudes and values, mental models of climate change, climate-related policy preferences, and their projections for future climate and future economic states given their selected policy preferences. Their projections are then compared to the projections generated by the computational model under the same parameterisations selected by the respondents.

Before we describe our approach we clarify the terminology and assumptions we use. This is important since we need to measure and compare a number of different concepts.

\footnotetext{
${ }^{1}$ Here, climate change beliefs refer to a person's opinion regarding i) whether climate change is happening or not ii) the proportion of climate change that has an anthropogenic source.
} 
Author-produced version of the article published in Sustainability Science, 2017, N ${ }^{\circ} 12(1)$, p. 45-64.

We define a mental model as in (Jones, Ross et al. 2011): 'personal, internal representations of external reality that people use to interact with the world around them [...They] are used to reason and make decisions and can be the basis of individual behaviors'. Mental models can be static or dynamic (Johnson-Laird 2001, Groesser and Schaffernicht 2012). We define a mental model as static if it does not include or does not explicitly account for the dynamical interactions between its components. For example, a static mental model may describe our understanding of how the climate system works today without accounting for how the system may change in the future. Alternatively, we define the mental model as dynamic if it is capable of accounting for system changes and for how the system can move from its current state to some future state. Because implementing a model numerically ensures dynamical and logical consistency (Boschetti 2012), we call the output of the computational model dynamically consistent. Notice that this implies that we use the term mental model in a system dynamic sense.

We define a cognitive signature as the set of attitudes, worldviews, and ideological beliefs which characterise an individual and affect the way she or he frames and understands a decisionmaking problem, in our case the climate change debate. A cognitive signature thus includes an attitudinal understanding of mental models. We employ the term cognitive signature rather than 'attitudinal understanding of mental models' because it is easier to follow in the text, which already discusses two types of models (mental and computational models). Also, 'cognitive signature' refers to more than the specific decision-making problem at hand, but includes a larger set of values and deeply-held beliefs which characterises all parts of an individual's self.

Given the above definitions, the purpose of this work is to understand to what extent and under what conditions people may employ dynamically consistent mental models in defining their policy support in relation to climate change and to what extent their cognitive signatures affect this process.

\section{Material and methods}


In some ways, mental models are the non-scientist's equivalent of the scientist's formal model of a system. A formal model specifies clearly and in operational terms a set of key variables in a system, and the relationships between those variables. In this paper, we consider a simple formal model capturing the relationships between population, climate change and global economic activity and we use its computational version.

In this section, we start by describing the computational model. It is designed so that, by changing some model parameters, we can represent fundamentally different mental models. The basis of the model is the interaction between population growth, the economy, and global warming, but the relative weight of the components and the importance of the related processes can be modified via parameter setting to represent mental models as seen from the standpoint of a citizen supporting free-market, eco-centric, or politically moderate views ${ }^{2}$. This effectively allows anyone using the model to explore the likely outcomes of different policy choices arising from different worldviews and different interpretations of the problem.

Next we describe an online survey designed to elicit each respondent's i) cognitive signature, ii) mental model of climate change (which is also the parameterisation of the computational model) iii) climate-related policy preferences and iv) climate and economic projections given the selected policy preferences. The latter are then compared to the projections obtained by the computational model under the same parameterisation as chosen by the respondent.

Figure 2 summarises the approach. The three columns (light blue background) refer to cognitive signature, mental model and computational model, respectively. A respondent is asked to select a number of model parameters (top panel, 'System understanding: How the system works now'). This is the elicitation phase in which the respondent reveals both his/her policy preferences and

\footnotetext{
${ }^{2}$ Here we employ the labels 'free-market supporter' for citizens who place priority on economic over ecological values (and vice versa for 'eco-centric' citizens), while acknowledging that concerns for environmental issues and support for market approaches are not necessarily mutually exclusive.
} 
understanding of how the systems works. Notice that the latter, according to the terminology we defined above, is the respondent's static mental model of the system in its current state.

Next, we need to 'run' the dynamics (middle panel, 'Dynamics: How the system changes in time'). This is carried out by the respondent using his/her mental model (middle column) as well as by the computational model under the same parameterisation (right hand side column). Next, we analyse and compare the projections from both the mental model and the computational model (bottom panel, 'Prediction: How the system may look in the future'). Finally, we study the relationships between a number of psychological constructs (the respondent's cognitive signature, left hand side column) and both the mental model's input and output. Figure 2 also contains a visual summary of our results, and these will be described more fully in the Results section. For now, though, note that blue (black) links represent positive (negative) statistically significant correlations $(\mathrm{p}<0.05)$ and link thickness maps correlation strength (see Table 5 and Table 6 for numerical values for the correlations). Crucially, notice that the absence of a link means a lack of statistically significant correlation. We now proceed by describing the computational model and the online questionnaire used to elicit both the mental model and the cognitive signature.

\section{a. The APE computational model}

In this study we use the activity-population-environment (APE) computational model (Grigg, Boschetti et al. 2011, Boschetti 2012). Here we present the model's main features; it is described thoroughly in Appendix A.

The public discourse on climate change focuses on two main aspects: the contribution of economic activities to global climate change through the release of greenhouse gases in the atmosphere; and the consequences of climate change on human well-being through its effects on the environment and economic activities. Thus, the basis of the computational model is the interaction between global population (which has an important influence on greenhouse gas emissions, and is 
Author-produced version of the article published in Sustainability Science, 2017, N ${ }^{\circ} 12(1)$, p. 45-64.

influenced by economic activity), global economic activity, represented by the GDP per capita (which influences the amount of greenhouse gases per capita released in the atmosphere), and global warming. This interaction is controlled by a number of input parameters. Among these, six are particularly significant for the climate change debate (see Table 1) since they hold an intuitive meaning in terms of a respondent's cognitive signature in general and his/her attitude towards climate change in particular. Climate Sensitivity (to $\mathrm{CO} 2$ concentration) and Critical Temperature (above which economic activity will be affected) define climate change's physical cause and avenue to impact, respectively, and thus represent beliefs and attitudes towards the science of climate change. Mitigation Cost and Human Carrying Capacity reflect beliefs about how economic and social processes affect, and are affected by, climate change: Mitigation Cost (expected cost of mitigation initiatives) reflects how we believe our economic system works, and Human Carrying Capacity reflects our belief about the extent to which our planet can sustain human life. Finally, Mitigation Target (how much to mitigate) and Mitigation Timeline (by when) are core targets of policy-making, since they represent the extent and urgency of mitigation initiatives. Importantly, the beliefs underlying these model parameter choices are influenced by and can be moulded to fit specific worldviews (Kunda 1990, Jost, Glaser et al. 2003, Feygina, Jost et al. 2010, Jost and Amodio 2012).

Participants were asked to select which of three or four options for each parameter (presented under Parameter Settings in Table 1) they believed to be true. These can take values in line with current scientific evidence or can fall outside this range. As in (Boschetti 2012), this choice can be mapped along a continuum going from a free-market-centric to an eco-centric view, reflecting different priorities placed on economic over ecological concerns (Dunlap, Van Liere et al. 2000, Price, Walker et al. 2014). For example, respondents can choose from 0 to $90 \%$ reduction in emissions (Mitigation Target) with 0 (90\%) being compatible with a free-market-centric (ecocentric) view. Similarly, respondents may believe that climate change will affect economic 
Author-produced version of the article published in Sustainability Science, 2017, N ${ }^{\circ} 12(1)$, p. 45-64.

activities (Critical Temperature) only when warming exceeds $5^{\circ} \mathrm{C}$, reflecting a free-market-centric beliefs in the economic system's resilience to climate change, or already when warming exceeds $1.7^{\circ} \mathrm{C}$, reflecting an eco-centric beliefs in the overall earth system's (including the economy) fragility to climate change (Kahan, Braman et al. 2007, Boschetti, Walker et al. 2015)

Given its inherent simplification, the APE computational model explores the dynamically consistent environmental and economic consequences of different sets of beliefs on how the climate system works and of how it may interact with policy preferences, by simulating the system's evolution to the year 2100. For example, a respondent may choose values for Climate Sensitivity and Critical Temperature which are or are not in line with scientific evidence and may choose policy preferences (Mitigation Target and Mitigation Timeline) in line with free-market-centric, moderate or eco-centric views. Whatever the choice, the model outputs are dynamically consistent, under the assumption that the APE model is a reasonable representation of people's assumptions about interactions between population, emissions, climate change and economic impacts.

There are a number of reasons why this computational model can be understood as a numerical implementation of a mental model and thus allows us to compare the output of the dynamically consistent mental models (which are simulated) with the output of the actual mental models as found among the general public:

1) The model is low-dimensional and focuses on three state variables. This is compatible with a vast literature which suggests that people have trouble representing the dynamical evolution of more than 2-4 variables (Stanovich 1999, Halford, Cowan et al. 2007);

2) The model can be represented diagrammatically in the form of a small network (See Fig.C. 1 in Appendix C) as is commonly done in the literature to describe or elicit mental models (Jones, Ross et al. 2011); 
3) The state variables (GDP, population, and warming) are part of everyday public discourse and the meaning of the model parameters (Table 1) can be easily explained to the respondents (see Appendix C);

4) While the model equations are fixed (see Appendix A), the effective model structure is controlled by the model parameters described above. For example, setting the Critical Temperature to $5^{\circ} \mathrm{C}$ effectively removes any link from the climate to the economy (see Fig.B. 1, in Appendix B). Similarly, setting the Mitigation Cost to zero prevents mitigation policy from affecting the economy. These would be classified as different mental models (rather than variation of a single model) according to a core principle on mental model theory which specifies that 'each mental model represents a possibility' (Johnson-Laird 2001).

5) Finally, the idea of using a computational model to implement a mental model is well established in the psychological literature (Johnson-Laird 2001, Johnson-Laird, Khemlani et al. 2015) and the idea of using a computational model to assess the performance of a mental model is well developed in the climate change and natural resource management literatures (Moxnes 1998, Moxnes and Saysel 2008, Sterman 2008).

While this discussion suggests that the APE computational model can be understood as representing mental models of climate change, we still need to ascertain whether it represents the mental models of the respondents in our study. We do so by analysing the online survey (see Section 5.a).

\section{b. Online survey}


We administered the survey online in July 2012 to a sample of 130 individuals (72 men, 58 women), broadly representative of the Australian population ${ }^{3}$. A copy of the full questionnaire can be found at: http://www.per.marine.csiro.au/staff/Fabio.Boschetti/Surveys/APE-MentalModels.pdf.

The purpose of the questionnaire was to assess the respondents' cognitive signatures as well as to elicit their mental models of climate change. In particular, it included measures of the following constructs:

1) Attitude toward the environment. Two measures were used here. First, participants' environmentalism was assessed by the question 'Do you consider yourself an environmentalist?' (1 = no, not at all; $2=$ no, not much; $3=$ a little; 4 = yes; 5 = yes, definitely). Second, using a scale we had previously tested (Boschetti, Richert et al. 2012), environmental commitment was assessed with seven questions (e.g., 'I am personally committed to preventing environmental problems'), each responded to on a scale from $1=$ strongly disagree to $5=$ strongly agree. Responses to negativelyworded items were reversed, and then all responses were averaged such that high scores indicate greater environmental commitment.

2) Attitude toward science. In order to evaluate the respondents' attitudes toward the specific model used in this study, we had aimed to assess respondents' attitudes toward computational models in general. Therefore, the respondents had to indicate their level of familiarity toward computational models by choosing the statement that best matched them among: "I do not know what computer modelling is", "I have a rough idea of what computer modelling is", "I have seen computer modelling at work or its results in some occasions", and "I am familiar with computer modelling”. Unfortunately, $22.3 \%$ of the respondents did not know what computational

\footnotetext{
${ }^{3}$ The panel used is administered by ORU, an online fieldwork company with QSOAP 'Gold Standard' and the new Global ISO 26362 standard accreditation. The ORU has a database of over 300,000 individuals from across Australia (http://www.theoru.com/). The online panel consisted of a group of community members who have explicitly agreed to take part in web-based surveys from time to time. In return they are offered a small non-cash incentive for completing such tasks, such as points towards shopping credits. The gender and age profile of the sample accords with the known population characteristics of Australians.
} 
modelling is. As a result, we adopted their attitude toward science (Boschetti, Richert et al. 2012) as a proxy. Attitude toward science was assessed using a 5-item scale (e.g., 'I believe science can provide solutions to environmental problems'). Responses to each item could range from $1=$ strongly disagree to $5=$ strongly agree. After recoding reverse-worded items and averaging, high scores indicate a more positive attitude toward science.

3) Time orientation. Environmental issues, and climate change in particular, are often described as having very slow dynamics. Hence, we wanted to analyse the relation between respondents' attitude toward the future and their parameter choices. We employed a short 7-item version of the Consideration of Future Consequences scale (Strathman, Gleicher et al. 1994). Items (e.g., 'I only act to satisfy immediate concerns, figuring the future will take care of itself') were responded to on a 5 -point scale, from $1=$ strongly disagree to $5=$ strongly agree. After recoding reverse-worded items and averaging, high scores indicate a greater willingness to delay immediate gratification.

4) Ideologies. The political implications of the climate change debate have been extensively studied (Dessai, Adger et al. 2004, Leiserowitz 2006, Kahan, Braman et al. 2007). We included the commonly-used Social Dominance Orientation (SDO) scale (Pratto, Çidam et al. 2013) and the Right-Wing Authoritarianism (RWA) scale (Heaven and Quintin 2003).

5) Expectation about the future evolution of Australia society. Following (Kashima, Shi et al. 2011), we asked whether respondents believe that by 2050 Australian society will be more or less safe, skilled, wealthy, honest and friendly. Responses ranged from $1=$ much less safe/skilled/wealthy/honest/friendly than now, to $5=$ much more than now.

6) Climate change opinions. We also included two questions to evaluate the extent to which the respondents believe in climate change. We asked i) if they believe climate change is happening (referred as Climate Change Q1) and ii) what proportion of it has an anthropogenic 
Author-produced version of the article published in Sustainability Science, 2017, N ${ }^{\circ} 12(1)$, p. 45-64.

source (Climate Change Q2). These questions were originally developed in (Leviston and Walker 2010).

7) Mental model - computational model parameterisation. The computational model was described to respondents, who were then presented with a description of each of the parameters and asked to select one of the three possible values (see Table 1 for the parameters and the options). Respondents were next asked to respond to three questions about their views on policies to achieve target human global $\mathrm{CO}_{2}$ emissions: 1) We should reduce human global emissions of $\mathrm{CO}_{2}$ by... (response options were $5 \%, 45 \%, 90 \%$, or 'there is no need to reduce out emissions ${ }^{4}$ ); 2) $90 \%$ of the goal chosen should be achieved by... (response options were 2020, 2060, 2100); 3) If we manage to reach the goal you chose, how much do you think it will cost... (response options were $0 \%$ of GDP, $10 \%$ of GDP, $20 \%$ of GDP). Finally, respondents were asked to predict the long-term impact of their choices on the model output variables (population size, wealth and warming) - that is, to mentally execute their internal mental models. Specifically, we asked "Assuming the policies you chose are implemented, what do you think will happen by 2100 compared to today?" For global population, global GDP, and global temperature, respondents indicated if they thought each would strongly decrease, slightly decrease, stay stable, slightly increase, or strongly increase.

\section{Results}

First, we analyse the respondents' mental models, as represented by their choices of APE computational model parameters. We examine their relational consistency by checking i) their internal consistency, ii) their relation to scientific evidence, and iii) their relation to the respondents' cognitive signatures. This will give us an indication on whether the respondents have understood the model description and whether, as assumed in (Boschetti 2012), the APE model is a reasonable representation of the respondents' mental models of climate change.

\footnotetext{
${ }^{4}$ Participants who provided this response were instructed to skip the next two questions.
} 
Author-produced version of the article published in Sustainability Science, 2017, N ${ }^{\circ} 12(1)$, p. 45-64.

Second, we analyse the projections to the year 2100 . Here we examine the dynamical consistency by checking i) the consistency between mental model and computational model projections, and ii) the relation between mental model input parameters and projections. We also investigate the cognitive consistency by comparing the relation between the respondents' choices of APE computational model parameters and their cognitive signature, and the relation between mental model projections and cognitive signatures. This will give us an indication of whether the respondents' mental models are dynamically consistent and whether the expectation of the system's future state is affected more by cognitive signatures or by the system dynamics implicit in their mental models.

\section{a. Input parameter choices and cognitive signatures}

Table 2 shows the distribution of the model parameters as chosen by the respondents. The parameter with strongest consensus among the respondents is Human Carrying Capacity: the majority of respondents (68.5\%) believe that the global Human Carrying Capacity is 15 billion people. As a result, this parameter does not provide much discriminatory power and we excluded it from subsequent analysis.

The distribution of beliefs about the climate change parameters matches quite well current scientific agreement (Cohen 1996, Ehrlich and Lui 1997, New, Liverman et al. 2011, Raupach, Canadell et al. 2011). Indeed, $68 \%$ of the respondents chose values for both the critical temperature and the climate sensitivity that fall within the range proposed by climate scientists.

Table 3 shows the correlations among the 6 model parameters chosen by the respondents. We coded the choices of Mitigation Target from 1 to 4, with 1 being the less ambitious mitigation policy (no reduction of greenhouse gases emissions) and 4 being the most ambitious (90\% reduction of greenhouse gases emissions). Similarly, we coded the other 5 parameters from 1 to 3 , with 1 representing: the least ambitious goal (for Mitigation Timeline); the most optimistic belief regarding 
the resilience of the system (for Climate Sensitivity, Critical Temperature and Human Carrying Capacity); or the most pessimistic belief regarding the Mitigation Cost. Respondents who chose a Mitigation Target of $0 \%$ did not select a value for the Mitigation Timeline and the Mitigation Cost, so we replaced their non-answers for these parameters by 1 in order to be able to compare the parameterisations. Thus, for each parameter, the lowest score stands for the most free-marketcentric view, and the highest score represents the most eco-centric view.

Respondents' choices of Mitigation Target, Mitigation Timeline, Climate Sensitivity and Critical Temperature are positively correlated. However, Mitigation Cost is correlated only with Mitigation Timeline and appears to be overestimated. One hypothesis to explain the lack of significant correlation between this parameter and the others is that people can interpret the Mitigation Cost in several ways. It can reveal either the importance we want to allocate to climate change mitigation, or our belief regarding the effect of mitigation policies on the economy. Because of this ambiguity, we excluded this parameter from subsequent analysis.

For the remaining analyses, we combine the Mitigation Target, Mitigation Timeline, Climate Sensitivity and Critical Temperature parameters into a single measure reflecting respondents' beliefs about climate change. We obtain this measure (called Average Belief) by averaging the 4 parameters; scores can range from 1 to 3 , and higher scores indicate more ecocentric views. This new measure has $\mathrm{M}=2.15, \mathrm{SD}=0.47$, and Cronbach's alpha $=0.59^{5}$.

Table 4 shows the means and standard deviations of the cognitive constructs, and their Pearson correlation with Average Belief. The correlations of each construct with Average Belief are in line with the literature, and are consistent with an eco-centric vs. free-market-centric polarisation. Moreover, we found a positive and significant correlation between the Average Belief measure and the Climate Change Q2 $(r=0.66, p<0.001)$. Thus, the more the respondents believe humans

\footnotetext{
${ }^{5}$ We rescaled the scores of Mitigation Target to 1 to 3 to ensure that the Average Belief scores are comprised between 1 and 3, 1 being the most market-centric score and 3 the most eco-centric
} 
Author-produced version of the article published in Sustainability Science, 2017, N ${ }^{\circ} 12(1)$, p. 45-64.

contribute to climate change, the more eco-centric parameterisation they chose. However, none of the measures of expectations about the future correlate significantly with Average Belief.

To summarise this section, the respondents' input parameter choices are i) reasonably aligned with scientific evidence (Table 1), ii) internally consistent (Table 2) and iii) consistent with the respondents' cognitive signatures pertinent to their view of how the world functions today (Table 3). In addition, no correlation is shown between the respondents' input parameter choices and their cognitive signatures pertinent to the future (Table 34). We interpret this to mean that i) the respondents have understood the description of the APE model reasonably well and ii) the APE model is a reasonable representation of the respondents' static mental model of climate change; that is, the APE model is a reasonable representation of how the respondents understand the climate change debate and the current state of the system.

\section{b. Respondents' predictions and cognitive signatures}

Table 5 shows the distribution of the respondents' predictions. Because of the heavy skew in responses for Global Population, this variable lacked discriminatory power and was excluded from subsequent analyses.

Next, we compare the respondents' predictions for global economic activity and global warming by 2100 with the outcomes obtained from running the APE model with their parameter choices. The model runs are shown and described in Appendix B.

The APE model generates numerical estimations of future warming and economic activity. Rather than asking respondents to generate numerical estimations, which would be cognitively difficult if not impossible for most, respondents were asked to indicate how global population, global GDP, and global temperature would change relative to today's state by choosing one of five fuzzy response options, 'strong decrease', 'decrease', 'more or less the same', 'increase', 'strong increase'. These options are purposely fuzzy, since a numerical answer would require, among other 
Author-produced version of the article published in Sustainability Science, 2017, N ${ }^{\circ} 12(1)$, p. 45-64.

challenges, a proper appreciation of the measurement units. As a result, there is some subjectivity in the way the five options are compared with the model numerical output. We assigned numerical ranges to each option. If the dynamically consistent model and the mental model predictions fall in the same range the prediction was identified as correct. For warming, the fuzzy classes were defined by the intervals $0.4-0.5^{\circ} \mathrm{C}$ (strong decrease), $0.5-0.7^{\circ} \mathrm{C}$ (decrease), $0.7-2.0^{\circ} \mathrm{C}$ (stable), $2.0-4.0^{\circ} \mathrm{C}$ (increase), $4 \cdot 0-5 \cdot 7^{\circ} \mathrm{C}$ (strong increase) above preindustrial temperatures. For human activity the fuzzy classes were defined by the intervals 0-2000 \$ (strong decrease), 2000-4000 \$ (decrease), 4000-10000 \$ (stable), 10000-23500 \$ (increase), 23500-38300 \$ (strong increase) per person. These classes were chosen to encompass the ranges of the computational model output as well as to allow for an equal number of classes below ('strongly decrease', 'slightly decrease') and above ('slightly increase', 'strongly increase') the current state ('stay stable').

Following this method, we found that only $11 \%$ of respondents correctly predicted the outcomes from the evolution of their own chosen assumptions about global economic activity and global warming. The main source of discrepancy lies in the fact that the respondents' intuitive expectations show a significant positive correlation $(0.35, \mathrm{p}<0.05)$ between the global economic activity predictions and the global warming predictions while the APE model predictions show a negative correlation $(-0.44, \mathrm{p}<0.05)$. The positive correlation in the respondents' predictions is found despite the fact that the survey specifically explained that the Critical Temperature assumption (see Appendix C) is about climate change impacting negatively on the economy.

Next, we search for variables which could explain respondents' predictions. Table 6 shows the Pearson correlations between the Average Belief measure, the cognitive constructs and the predictions for Global Warming and for Global Activity.

First, we observe that the respondents' predictions are not significantly correlated with Average Beliefs. Moreover, respondents' predictions are not correlated with any of SDO, RWA, or attitudes toward the environment. Recall that SDO, RWA, and attitudes toward the environment are 
significantly correlated with the Average Beliefs in Table 4. Conversely, the expectations about a future Australian society show some correlations with the respondents' predictions. Among these, the strongest correlations are displayed by the expectation of future wealth. Respondents who expect a wealthier future in Australia also predict a warmer future. Respondents who expect a more skilled future in Australia predict a higher level of warming. This may be tentatively interpreted as people associating skills with technology, and technology with industrial production. In addition, unlike SDO, RWA, and attitudes toward the environment, these expectations about the future do not show any statistically significant correlation with the Average Beliefs (Table 4). All these relationships are summarized by the links in Figure 2.

This leads to the identification of a second static mental model, describing how the world may look in the far future (year 2100). This second static mental model shows i) a significant positive correlation between predictions of global activity and global warming, ii) correlations with some (but not all) of the cognitive signature variables pertaining to the future and, iii) no correlation with the static mental model of how the world functions today.

In particular, there is no general linear relationship between the respondents' static mental model of how the world functions today, on the one hand, and their static mental model of how the world may look like in the future, on the other. Three hypotheses could explain this result. First, the relationship between these static mental models could be non-linear. Second, static mental models and predictions could be linked by different dynamics among different groups of respondents, which cannot be captured by a single model. And finally, respondents' mental models could be dynamically inconsistent. Also, of course, these different hypotheses could be combined. We address these three hypotheses next.

The first hypothesis seems unlikely. We know that even highly educated and scienceliterate people fundamentally misunderstand climate dynamics (Sterman and Sweeney 2007, 
Sterman 2008, Guy, Kashima et al. 2014). From this, it seems unlikely that the general public would engage in non-linear mental modelling.

To explore the relevance of the second hypothesis, we split the sample into two groups that shared similar worldviews and were thus likely to have similar mental models: an eco-centric group (62 respondents whose Average Belief measure was above the median value of 2.17) and a freemarket-centric one (68 respondents whose Average Belief measure was below or equal to the median value $)^{6}$. In neither group did we find a significant correlation between the respondents' parameterisations and their predictions. Even more surprisingly, in neither group was there a significant correlation between Climate Change Q2 (estimated proportion of climate change attributable to anthropogenic sources) and their predictions regarding global warming trends. While it is known that people tend to interpret climate information in a way that confirms their preexisting beliefs (Kahan 2013), our results suggest that respondents did not take their beliefs regarding climate change into account when predicting the future state of the system.

Hence, our results are most consistent with the third hypothesis, according to which the respondents' mental models are not dynamically consistent. One way this dynamic inconsistency may manifest itself is by holding two static mental models (one of how the system works today and one of how the word may function in the future) without assessing whether it is dynamically possible to transition from the first to the second. We further discuss this below.

\section{Discussion and conclusion}

Sustainability challenges are inherently complex and dynamic, and have a long time course. Policy formulation, policy support, behaviour change, and other forms of tackling sustainability challenges require a deeper understanding of complex systems, among policy makers and the general public alike. The mental models policy makers and the public have of how complex,

\footnotetext{
${ }^{6}$ We considered the sum of the score of Mitigation Target (not rescaled), Mitigation Timeline, Climate Sensitivity, and Critical Temperature.
} 
dynamic, natural systems operate undergird decisions and behaviours. To the extent that mental models lack verisimilitude, especially about projections of the future states of systems, then decisions and behaviours are likely to be misdirected, ineffectual, or even counterproductive in terms of moving toward greater sustainability. Our study here addressed the question of the consistency between mental models and computational models, and between mental models of a system at present and of that system at some future time.

We found a significant mismatch between the outputs of the mental models 'run' by the respondents and by the computational model, under the same parameterisation. This highlights a lack of dynamical consistency in respondents' mental models. Usually, the literature explains these types of mismatches either in terms of bias driven by political ideology and climate change beliefs (Feygina, Jost et al. 2010, Kahan, 2013) or in terms of poor understanding of the simple foundations of system dynamics (Moxnes and Saysel 2008, Sterman 2008). However, we detect a degree of relational consistency between the attitudinal and the system dynamic view of mental models which does not support either of these two explanations. Finally, we find a lack of cognitive consistency in the respondents' selection of choices among available narratives about how the system works today and narratives about the future, by treating them as two independent and static representations. This suggests the importance of a dual-process model of how citizens define their own climate change beliefs and how they assess the consequences of those beliefs. Ideology and worldviews correlate with how we believe the system works today and what we should do; expectations about the future correlate with how we believe the system will look in the future.

It is well-known that people are often poor at mentally managing system dynamics. One common suggestion for bolstering policy support, behaviour change, and other desired outcomes, is for scientists and others to improve people's comprehension of systems and system dynamics. Our results here suggest that such a strategy would likely have limited benefit. Our results suggest that when thinking about climate change and the future, people maintain two static mental models, one 
Author-produced version of the article published in Sustainability Science, 2017, N ${ }^{\circ} 12(1)$, p. 45-64.

The original publication is available at https://link.springer.com

of today and one of the future. These appear to be dynamically inconsistent. Poor understanding of system dynamics is compatible with human cognitive limitations identified in the literature (Sterman and Sweeney 2002, Moxnes and Saysel 2008, Sterman 2008). However, poor understanding of system dynamics is unlikely the only explanation of our results, since it does not explain why the static mental model of the future should show some correlation with the cognitive signatures pertaining to the future and not to the present and why the static mental model of the present should behave in a diametrically opposite way. Our results suggest a novel alternative explanation, pointing to a fundamental difference between the cognitive and affective resources used in model formulation vs. model evaluation.

The correlations between the two static mental models with different components of the respondents' cognitive signatures could stem from a mismatch between the cognitive resources used to formulate the static mental model of the present climate change issue, on the one hand, and the cognitive resources used to predict its dynamical evolution on the other. This would suggest that model formulation and dynamic assessment are treated as two different processes, thus overlooking the dynamical constraints which should link the two static models. This dual-process hypothesis is consistent with Temporal Construal Theory (Trope and Liberman 2003), according to which the far future is the realm of abstract representations that do not necessarily refer, or need to refer, to specific events or specific plans. This view is also consistent with the results in (Bain, Hornsey et al. 2012) which suggest that framing climate policies in terms of the core human values, rather than ideologies, can affect preferred mitigation choices. Indeed, since ideologies are correlated with mental models of how the world works today, framing climate policies in terms of ideologies could bring the focus on the present and induce people to overlook the future consequences of these policies. Framing climate policies in terms of the core human values could instead bring the focus on more abstract representations of how people would like the world to work in the future and induce them to choose their preferred policies consequently. 
Finally, since we found a positive correlation between predictions regarding warming and wealth, the respondents to our survey seem to believe that wealth may be diminished by initiatives to combat climate change, not by climate change itself. This could represent an associative bias arising from the oversimplified climate change debate in the media, describing the climate change debate along an eco-centric vs. free-market centric polarization which portraits a dichotomy between 'economic and hedonistic' vs. 'environmental and frugal' choices. We detected a similar dichotomy in previous work with Australian citizens (Boschetti, Fulton et al. 2014).

Although people's static mental models of climate change seem fairly consistent when observed in isolation, they also seem to lack dynamical consistency when time evolution is considered. This is probably unsurprising if we consider that long-term predictions over many decades are rarely discussed, contemplated, or even imagined. Indeed, our previous research suggests that many respondents are rarely, if ever, asked to formulate long term projections and that when they do so they have to rely on cognitive resources different from those usually engaged in the climate change discourse (Boschetti, Fulton et al. 2014).

Our results add to the ample literature on the impact on effective decision-making of logical fallacies (Stanovich 1999, Kahneman 2011), numeracy and scientific literacy (Kahan, Peters et al. 2012, Gerardi, Goette et al. 2013, Guy, Kashima et al. 2014), and poor appreciation of dynamical processes. Specifically, our results highlight a different causal path. Our respondents seem to be drawing on a limited number of narratives available (as obtained from the media, peers, scientific literature, etc) in choosing a description of the problem (on a free-market-support vs. eco-centric dimension) and a possible outcome (on an 'economic and hedonistic' vs. 'environmental and frugal' dimension). Further, they appear to be using different sets of cognitive tools for the two choices, leading to description-outcome pairings which are both dynamically and cognitively inconsistent. Neither set of cognitive tools seems to focus on evaluating the degree of consistency between the two outcomes. The inconsistency between the respondents' descriptions of the climate system and 
Author-produced version of the article published in Sustainability Science, 2017, N ${ }^{\circ} 12(1)$, p. 45-64.

The original publication is available at https://link.springer.com

their predictions supports the hypothesis that people use entirely static mental models to reason about climate change.

We suggest that computational modelling and cognitive processes such as self-reflection, slow thinking, critical analysis and abstraction would help to address the cognitive challenges arising from dynamical processes (Dorner 1996, Stanovich 1999, Kahneman 2011) which can be found in many sustainability issues. We expect they would also be beneficial (as suggested in (Costanza 2000)) in addressing the gap between model formulation (how we think the world works today) and projections (how we think the world may work in the future). It could also be useful to present people with familiar analogies, such as the evolution of a disease and the possible effects of different cures, in order to help them understand the dynamic implications of climate change (Stern and Raimi 2015).

Moreover, our study suggests an alternative way in which computational modelling could be employed in similar training. Computational models can be run forwards or inversely (Tarantola 1987). Loosely speaking, forward modelling fixes the initial state and calculates future states (as in this work), while inverse modelling fixes the future state and asks what initial states may lead to it. Our finding that expectations about the future affect the assessment of the model dynamics but not the choice of the model itself has some important implications. Debates about anthropogenic climate change and the urgency or otherwise of significant mitigation action are wracked by ideologically-based differences. Those debates rest more on analyses of the present than of the future. Inverse modelling may help to bring aspirations to the fore, pushing the role of ideologies and attitudes into the background, and perhaps will lead to a better evaluation of choices currently available to us. This would suggest that back-casting from shared visions (as discussed in (Wiek and Iwaniec 2014) could be enhanced by the use of numerical models and well developed numerical optimisation routines, by either formal (Tarantola 1987) or informal approaches (Boschetti, de La Tour et al. 2010). Our work reported here opens the door to an approach where 
dynamical inconsistencies between policy choices and desired futures are made explicit to the public and the causes of these inconsistencies are explored and perhaps resolved via the use of simple computational models. We suggest that this approach could be extended to a wide range of ecological and socio-economic problems.

\section{Acknowledgements:}

The research reported in this paper was supported by funds from CSIRO's Climate Adaptation Flagship. 


\section{References}

Bain, P. G., M. J. Hornsey, R. Bongiorno and C. Jeffries (2012). "Promoting pro-environmental action in climate change deniers." Nature Climate Change 2(8): 600-603.

Boschetti, F. (2012). "Causality, emergence, computation and unreasonable expectations." Synthese 185(2): 187-194.

Boschetti, F. (2012). "A computational model of a mental model used to reason about climate change." Environmental Science \& Policy 15(1): 125-135.

Boschetti, F., A. de La Tour, E. Fulton and R. Little (2010). "Interactive modelling for natural resource management." Environmental Modelling and Software 25(10): 1075-1085.

Boschetti, F., B. Fulton and N. Grigg (2014). "Citizens' views of Australia's future to 2050." Sustainability Submitted.

Boschetti, F., E. Fulton and N. Grigg (2014). "Citizens' Views of Australia's Future to 2050." Sustainability 7(1): 222-247.

Boschetti, F., C. Richert, I. Walker, J. Price and L. Dutra (2012). "Assessing attitudes and cognitive styles of stakeholders in environmental projects involving computer modelling." Ecological Modelling 247: 98-111.

Boschetti, F., I. Walker and J. Price (2015). "Modelling and attitudes towards the Future." Ecological Modelling Submitted.

Boyd, J. N. and P. G. Zimbardo (1997). "Constructing time after death - The transcendental-future time perspective." Time \& Society 6(1): 35-54.

Cohen , J. (1996). How Many People Can the Earth Support? New York, W. W. Norton \& Company Costanza, R. (2000). "Social goals and the valuation of ecosystem services." Ecosystems 3(1): 4-10. Craik, K. J. W. (1943). The nature of explanation. Cambridge Eng., University Press.

Cronin, M. A., C. Gonzalez and J. D. Sterman (2009). "Why don't well-educated adults understand accumulation? A challenge to researchers, educators, and citizens." Organizational Behavior and Human Decision Processes 108(1): 116-130.

Crutchfield, J. P. (1994). "The Calculi of Emergence: Computation, Dynamics, and Induction." Physica D 75: 11-54.

D'Argembeau, A. (2012). Autobiographical memory and future thinking. Understanding autobiographical memory: Theories and approaches. D. Berntsen and D. C. Rubin. Cambridge, Cambridge University Press.

D'Argembeau, A., C. Lardi and M. Van der Linden (2012). "Self-defining future projections: Exploring the identity function of thinking about the future." Memory 20(2): 110-120. D'Argembeau, A., O. Renaud and M. Van der Linden (2011). "Frequency, Characteristics and Functions of Future-oriented Thoughts in Daily Life." Applied Cognitive Psychology 25(1): 96-103. D'Argembeau, A. and M. Van der Linden (2007). "Emotional aspects of mental time travel." Behavioral and Brain Sciences 30(3): 320-+.

Dessai, S., W. N. Adger, M. Hulme, J. Turnpenny, J. Köhler and R. Warren (2004). "Defining and experiencing dangerous climate change." Climatic Change 64(1-2): 11-25.

Dorner, D. (1996). The Logic Of Failure: Recognizing And Avoiding Error In Complex Situations. Ney York, Metropolitan Books.

Dunlap, R. E., K. D. Van Liere, A. G. Mertig and R. E. Jones (2000). "Measuring endorsement of the new ecological paradigm: A revised NEP scale." Journal of Social Issues 56(3): 425-442.

Eagly, A. H. and S. Chaiken (1993). The psychology of attitudes, Harcourt Brace Jovanovich College Publishers. 
Author-produced version of the article published in Sustainability Science, 2017, № 12(1), p. 45-64.

Ehrlich, I. and F. Lui (1997). "The problem of population and growth: A review of the literature from Malthus to contemporary models of endogenous population and endogenous growth." Journal of Economic Dynamics and Control 21(1): 205-242.

Feygina, I., J. T. Jost and R. E. Goldsmith (2010). "System Justification, the Denial of Global Warming, and the Possibility of "System-Sanctioned Change"." Personality and Social Psychology Bulletin 36(3): 326-338.

Gagnon Thompson, S. C. and M. A. Barton (1994). "Ecocentric and anthropocentric attitudes toward the environment." Journal of Environmental Psychology 14(2): 149-157.

Gerardi, K., L. Goette and S. Meier (2013). "Numerical ability predicts mortgage default." Proceedings of the National Academy of Sciences of the United States of America 110(28): 1126711271.

Greca, I. M. and M. A. Moreira (2000). "Mental models, conceptual models, and modelling." International Journal of Science Education 22(1): 1-11.

Grigg, N. J., F. Boschetti, M. Brede and J. J. Finnigan (2011). "A probabilistic approach to exploring low-dimensional global dynamics." Procedia Environmental Sciences 6: 122-135.

Groesser, S. N. and M. Schaffernicht (2012). "Mental models of dynamic systems: taking stock and looking ahead." System Dynamics Review 28(1): 46-68.

Guy, S., Y. Kashima, I. Walker and S. O'Neill (2014). "Investigating the effects of knowledge and ideology on climate change beliefs." European Journal of Social Psychology 44(5): 421-429. Halford, G. S., R. Baker, J. E. McCredden and J. D. Bain (2005). "How many variables can humans process?" Psychological Science 16(1): 70-76.

Halford, G. S., N. Cowan and G. Andrews (2007). "Separating cognitive capacity from knowledge: a new hypothesis." Trends in Cognitive Sciences 11(6): 236-242.

Heath, Y. and R. Gifford (2006). "Free-Market Ideology and Environmental Degradation."

Environment and Behavior 38(1): 48-71.

Heaven, P. C. L. and D. S. Quintin (2003). "Personality factors predict racial prejudice." Personality and Individual Differences 34(4): 625-634.

Hohwy, J. (2013). The predictive mind, Oxford University Press.

Inayatullah, S. (2004). Causal Layered Analysis: Theory, historical context, and case studies. The Causal Layered Analysis (CLA) Reader: Theory and Case Studies of an Integrative and

Transformative Methodology. S. Inayatullah. Taipei, Taiwan, Tamkang University Press: 8-49. Johnson-Laird, P. N. (1983). Mental models : towards a cognitive science of language, inference and consciousness. Cambridge Cambridgeshire ; New York, Cambridge University Press. Johnson-Laird, P. N. (2001). "Mental models and deduction." Trends in Cognitive Sciences 5(10): 434-442.

Johnson-Laird, P. N. (2013). "Mental models and cognitive change." Journal of Cognitive Psychology 25(2): 131-138.

Johnson-Laird, P. N., S. S. Khemlani and G. P. Goodwin (2015). "Logic, probability, and human reasoning." Trends Cogn Sci 19(4): 201-214.

Jones, N. A., H. Ross, T. Lynam, P. Perez and A. Leitch (2011). "Mental Models: An Interdisciplinary Synthesis of Theory and Methods." Ecology and Society 16(1): 46. [online] URL: http://www. ecologyandsociety.org/vol16/iss1/art46/.

Jost, J. T. and D. M. Amodio (2012). "Political ideology as motivated social cognition: Behavioral and neuroscientific evidence." Motivation and Emotion 36(1): 55-64.

Jost, J. T., J. Glaser, A. W. Kruglanski and F. J. Sulloway (2003). "Political conservatism as motivated social cognition." Psychological bulletin 129(3): 339.

Kahan, D. (2013). "Ideology, motivated reasoning, and cognitive reflection: An experimental study." Judgment and Decision Making 8(4): 407-424. 
Kahan, D. M., D. Braman, P. Slovic, J. Gastil and G. L. Cohen (2007). "The Second National Risk and Culture Study: Making Sense of - and Making Progress In - The American Culture War of Fact." GWU Legal Studies Research Paper No. 370.

Kahan, D. M., D. Braman, P. Slovic, J. Gastil and G. L. Cohen (2007). "The Second National Risk and Culture Study: Making Sense of - and Making Progress In - The American Culture War of Fact." GWU Legal Studies Research Paper: No.-370.

Kahan, D. M., E. Peters, M. Wittlin, P. Slovic, L. L. Ouellette, D. Braman and G. Mandel (2012). "The polarizing impact of science literacy and numeracy on perceived climate change risks." Nature Clim. Change 2(10): 732-735.

Kahneman, D. (2011). Thinking, fast and slow. New York, Farrar, Straus and Giroux.

Kashima, Y., J. Q. Shi, K. Tsuchiya, E. S. Kashima, S. Y. Y. Cheng, M. Manchi and S. H. Shin (2011). "Globalization and Folk Theory of Social Change: How Globalization Relates to Societal Perceptions about the Past and Future." Journal of Social Issues 67(4): 696-715.

Kunda, Z. (1990). "The Case for Motivated Reasoning." Psychological Bulletin 108(3): 480-498.

Leiserowitz, A. (2006). "Climate Change Risk Perception and Policy Preferences: The Role of Affect, Imagery, and Values." Climatic Change 77(1-2): 45-72.

Leviston, Z. and I. A. Walker (2010). Baseline Survey of Australian Attitudes to Climate Change: Preliminary Report. N. R. F. C. Adaptation. Perth, CSIRO Ecosystem Sciences.

Liberman, N. and Y. Trope (1998). "The role of feasibility and desirability considerations in near and distant future decisions: A test of temporal construal theory." Journal of Personality and Social Psychology 75(1): 5-18.

Moxnes, E. (1998). "Overexploitation of renewable resources: the role of misperceptions." Journal of Economic Behavior and Organization 37(1): 107-127.

Moxnes, E. (2000). "Not only the tragedy of the commons: misperceptions of feedback and policies for sustainable development." System Dynamics Review 16(4): 325-348.

Moxnes, E. and A. K. Saysel (2008). "Misperceptions of global climate change: information policies." Climatic Change 93(1-2): 15-37.

Moxnes, E. and A. K. Saysel (2009). "Misperceptions of global climate change: information policies." Climatic Change 93(1-2): 15-37.

New, M., D. Liverman, H. Schroder and K. Anderson (2011). "Four degrees and beyond: the potential for a global temperature increase of four degrees and its implications." Philosophical Transactions of the Royal Society A: Mathematical, Physical and Engineering Sciences 369(1934): 6-19.

Nisbet, M. C. and E. Markowitz (2015). "Expertise in an Age of Polarization: Evaluating Scientists' Political Awareness and Communication Behaviors." Annals of the American Academy of Political and Social Science 658: 136-154.

Norman, D. A. (1987). Some observations on mental models. Human-computer interaction. R. M. Baecker and W. A. S. Buxton, Morgan Kaufmann Publishers Inc.: 241-244. Nowak, A., A. Rychwalska and W. Borkowski (2013). "Why simulate? to develop a mental model." Journal of Artificial Societies and Social Simulation 16(3): 12.

Pratto, F., A. Çidam, A. L. Stewart, F. B. Zeineddine, M. Aranda, A. Aiello, X. Chryssochoou, A. Cichocka, J. C. Cohrs, K. Durrheim, V. Eicher, R. Foels, P. Górska, I.-C. Lee, L. Licata, J. H. Liu, L. Li, I. Meyer, D. Morselli, O. Muldoon, H. Muluk, S. Papastamou, I. Petrovic, N. Petrovic, G. Prodromitis, F. Prati, M. Rubini, R. Saab, J. v. Stekelenburg, J. Sweetman, W. Zheng and K. E. Henkel (2013). "Social Dominance in Context and in Individuals: Contextual Moderation of Robust Effects of Social Dominance Orientation in 15 Languages and 20 Countries." Social Psychological and Personality Science. 
Price, J. C., I. A. Walker and F. Boschetti (2014). "Measuring cultural values and beliefs about environment to identify their role in climate change responses." Journal of Environmental Psychology 37(0): 8-20.

Quinn, N. (2005). How to reconstruct schemas people share, from what they say, Citeseer. Raupach, M. R., J. G. Canadell, P. Ciais, P. Friedlingstein, P. J. Rayner and C. M. Trudinger (2011). "The relationship between peak warming and cumulative $\mathrm{CO} 2$ emissions, and its use to quantify vulnerabilities in the carbon-climate-human system." Tellus B: no-no.

Raupach, M. R., G. Marland, P. Ciais, C. Le Quere, J. G. Canadell, G. Klepper and C. B. Field (2007). "Global and regional drivers of accelerating $\mathrm{CO} 2$ emissions." Proceedings of the National Academy of Sciences of the United States of America 104(24): 10288-10293.

Schwartz, S. H. (1992). "Universals in the content and structure of values: Theoretical advances and empirical tests in 20 countries." Advances in experimental social psychology 25(1): 1-65. Shalizi, C. R. and J. P. Crutchfield (2001). "Computational mechanics: Pattern and prediction, structure and simplicity." Journal of Statistical Physics 104(3-4): 817-879.

Spreng, R. N. and B. Levine (2006). "The temporal distribution of past and future autobiographical events across the lifespan." Memory \& Cognition 34(8): 1644-1651.

Stanovich, K. (1999). Who is rational? studies of individual differences in reasoning. Mahwah, NJ, Lawrence Erlbaum Associates.

Stawarczyk, D., H. Cassol and A. D'Argembeau (2013). "Phenomenology of future-oriented mindwandering episodes." Frontiers in Psychology 4: 425.

Sterman, J. D. (2008). "Risk Communication on Climate: Mental Models and Mass Balance." Science 322(5901): 532-533.

Sterman, J. D. and L. B. Sweeney (2002). "Cloudy skies: assessing public understanding of global warming." System Dynamics Review 18(2): 207-240.

Sterman, J. D. and L. B. Sweeney (2007). "Understanding public complacency about climate change: adults'mental models of climate change violate conservation of matter." Climatic Change 80(3-4): 213-238.

Stern, P. C. and K. T. Raimi (2015). "Simple Mental Models for Informing Climate Choices." Social Research: An International Quarterly 82(3).

Strathman, A., F. Gleicher, D. S. Boninger and C. S. Edwards (1994). "The Consideration of Future Consequences - Weighing Immediate and Distant Outcomes of Behavior." Journal of Personality and Social Psychology 66(4): 742-752.

Suddendorf, T. and M. C. Corballis (2007). "The evolution of foresight: What is mental time travel, and is it unique to humans?" Behavioral and Brain Sciences 30(3): 299-+.

Sweeney, L. B. and J. D. Sterman (2000). "Bathtub dynamics: initial results of a systems thinking inventory." System Dynamics Review 16(4): 249-286.

Tarantola, A. (1987). Inverse Problem Theory. Amsterdam, Elsevier.

Trope, Y. and N. Liberman (2003). "Temporal construal." Psychological Review 110(3): 403-421. Wiek, A. and D. Iwaniec (2014). "Quality criteria for visions and visioning in sustainability science." Sustainability Science 9(4): 497-512.

Wiek, A., L. Withycombe and C. L. Redman (2011). "Key competencies in sustainability: a reference framework for academic program development." Sustainability Science 6(2): 203-218.

Zimbardo, P. G. and J. N. Boyd (1999). "Putting time in perspective: A valid, reliable individualdifferences metric." Journal of Personality and Social Psychology 77(6): 1271-1288. 


\section{Tables}

Table 1: The model parameters which capture climate change beliefs: Parameter name and abbreviation (column 1), their meaning (column 2), and the numerical choices offered to the respondents (column 3). Parameter choices are ordered left-to-right according to eco-centric versus free-market-centric attitudes (Gagnon Thompson and Barton 1994, Heath and Gifford 2006).

\begin{tabular}{|c|c|c|}
\hline Parameters & Meaning & Parameter settings \\
\hline $\begin{array}{l}\text { Mitigation Target } \\
\text { (Mit } \text { Target })\end{array}$ & Target percentage reduction in emissions & $90,45,5,0(\%)$ \\
\hline $\begin{array}{l}\text { Mitigation Timeline } \\
\qquad\left(\text { Mit }_{E n d}\right)\end{array}$ & Year when the target mitigation is achieved & $2020,2060,2100$ \\
\hline $\begin{array}{l}\text { Climate Sensitivity } \\
\qquad(\lambda)\end{array}$ & $\begin{array}{c}\text { Increase in global average temperature per } \\
\text { doubling of } \mathrm{CO}_{2} \text { in the atmosphere }\end{array}$ & $3.4,2.2,1.0\left({ }^{\circ} \mathrm{C}\right)$ \\
\hline $\begin{array}{l}\text { Critical Temperature } \\
\qquad\left(\Delta T_{C r i t}\right)\end{array}$ & $\begin{array}{l}\text { The increase in temperature above which } \\
\text { economic activity will be affected }\end{array}$ & $1.7,3.3,5.0\left({ }^{\circ} \mathrm{C}\right)$ \\
\hline Mitigation Cost $\left(\right.$ Mit $\left._{\text {Cost }}\right)$ & Cost of mitigation in $\%$ of global GDP & $0,10,20(\%)$ \\
\hline $\begin{array}{l}\text { Human Carrying } \\
\text { Capacity }(K)\end{array}$ & $\begin{array}{c}\text { Maximum number of people the Earth could } \\
\text { sustain }\end{array}$ & $15,27,40\left(* 10^{9}\right)$ \\
\hline
\end{tabular}


Author-produced version of the article published in Sustainability Science, 2017, N ${ }^{\circ} 12(1)$, p. 45-64.

The original publication is available at https://link.springer.com

Doi: 10.1007/s11625-016-0384-2

Mental models of climate change

Table 2: Percentage distribution of respondents' parameter choices $(\mathrm{N}=130)$.

\begin{tabular}{|c|c|c|}
\hline Parameters & Possible values & $\begin{array}{c}\text { Percentage of } \\
\text { respondents } \\
(\%)\end{array}$ \\
\hline \multirow{4}{*}{ Mitigation Target } & $90 \%$ & 13.08 \\
\hline & $45 \%$ & 44.62 \\
\hline & $5 \%$ & 32.31 \\
\hline & $0 \%$ & 10.00 \\
\hline \multirow{4}{*}{ Mitigation Timeline } & $\mathrm{NA}^{7}$ & 10.00 \\
\hline & 2020 & 49.23 \\
\hline & 2060 & 33.85 \\
\hline & 2100 & 6.92 \\
\hline \multirow{3}{*}{ Climate Sensitivity } & $3.4^{\circ} \mathrm{C}$ & 30.77 \\
\hline & $2.2^{\circ} \mathrm{C}$ & 47.69 \\
\hline & $1.0^{\circ} \mathrm{C}$ & 21.54 \\
\hline \multirow{3}{*}{ Critical Temperature } & $1.7^{\circ} \mathrm{C}$ & 34.62 \\
\hline & $3.3^{\circ} \mathrm{C}$ & 43.85 \\
\hline & $5.0^{\circ} \mathrm{C}$ & 21.54 \\
\hline \multirow{4}{*}{ Mitigation Cost } & $\mathrm{NA}^{8}$ & 10.00 \\
\hline & $0 \%$ of the GDP & 10.77 \\
\hline & $10 \%$ of the GDP & 49.23 \\
\hline & $20 \%$ of the GDP & 30.00 \\
\hline \multirow{3}{*}{ Human Carrying Capacity } & 15 billion & 68.46 \\
\hline & 27 billion & 23.08 \\
\hline & 40 billion & 8.46 \\
\hline
\end{tabular}

${ }^{7}$ The respondents who chose $0 \%$ for the parameter Mitigation Target were not asked to choose a value for the Mitigation Timeline.

${ }^{8}$ The respondents who chose $0 \%$ for the parameter Mitigation Target were not asked to choose a value for the Mitigation Cost. 
Table 3: Pearson correlations among respondents' selections on the 6 dynamic mental model parameters

\begin{tabular}{|c|ccccc|}
\cline { 2 - 5 } \multicolumn{1}{c|}{} & $\begin{array}{c}\text { Mitigation } \\
\text { Timeline }\end{array}$ & $\begin{array}{c}\text { Climate } \\
\text { Sensitivity }\end{array}$ & $\begin{array}{c}\text { Critical } \\
\text { Temperature }\end{array}$ & Mitigation Cost & $\begin{array}{c}\text { Earth carrying } \\
\text { capacity }\end{array}$ \\
\hline $\begin{array}{c}\text { Mitigation Target } \\
\text { Mitigation } \\
\text { Timeline }\end{array}$ & $0.26^{*}$ & $0.47^{*}$ & $0.37^{*}$ & 0.14 & -0.02 \\
Climate Sensitivity & - & $0.22^{*}$ & 0.10 & $0.32^{*}$ & $0.21^{*}$ \\
$\begin{array}{c}\text { Critical } \\
\text { Temperature } \\
\text { Mitigation Cost }\end{array}$ & - & $0.27^{*}$ & -0.02 & $0.21^{*}$ \\
\hline
\end{tabular}

$\mathrm{N}=130 . *$ : $\mathrm{p}$-value $<0.05$.

Table 4: Means and standard deviations of the cognitive constructs and their correlation with the Average Belief measure.

\begin{tabular}{|c|c|c|c|}
\hline Mean & Standard & Construct & Correlation with \\
\hline 3.57 & 0.63 & Time orientation & $0.43^{*}$ \\
\hline 2.11 & 0.65 & Social Dominance Orientation & $-0.42^{*}$ \\
\hline 3.62 & 0.83 & Right-Wing Authoritarianism & $-0.20^{*}$ \\
\hline 3.72 & 0.61 & Attitude toward science & $0.28^{*}$ \\
\hline 2.90 & 1.05 & Environmental commitment & $0.34^{*}$ \\
\hline 3.67 & 0.56 & Environmentalism & $0.66^{*}$ \\
\hline 2.37 & 0.93 & Future safe & 0.05 \\
\hline 2.40 & 0.86 & Future honest & 0.07 \\
\hline 2.52 & 0.93 & Future friendly & 0.06 \\
\hline 2.75 & 1.14 & Future skilled & 0.10 \\
\hline 2.61 & 1.07 & Future wealthy & 0.08 \\
\hline
\end{tabular}

The scores for each construct are coded from 1 to 5, 1 being the lowest score on the construct and 5 being the highest. $N=130 . *$ : $p<0.05$. 
Author-produced version of the article published in Sustainability Science, 2017, $\mathrm{N}^{\circ} 12(1)$, p. 45-64.

Table 5: Distribution of respondents' predictions $(\mathrm{N}=130)$

Variable

Possible evolution by 2100
Percentage of respondents

$(\%)$

\begin{tabular}{ccc}
\hline & Will decrease & 14.62 \\
Global Population & Will stay stable & 24.62 \\
& Will increase & 60.77 \\
\hline \multirow{2}{*}{ Global Economic Activity } & Will decrease & 21.54 \\
& Will stay stable & 32.31 \\
& Will increase & 46.15 \\
\hline Global Warming & Will decrease & 11.54 \\
& Will stay stable & 33.85
\end{tabular}

Table 6: Correlations between the Average Belief measure, the cognitive constructs and the respondents' predictions.

\begin{tabular}{|c|c|c|}
\hline Construct & $\begin{array}{c}\text { Correlation with Global } \\
\text { Warming prediction }\end{array}$ & $\begin{array}{c}\text { Correlation with Global } \\
\text { Activity prediction }\end{array}$ \\
\hline Average Belief & 0.10 & 0.00 \\
\hline Social Dominance Orientation & 0.06 & 0.11 \\
\hline Right-Wing Authoritarianism & 0.00 & 0.02 \\
\hline Attitude toward science & 0.10 & 0.01 \\
\hline Environmental commitment & -0.07 & -0.07 \\
\hline Environmentalism & 0.11 & 0.01 \\
\hline Time Orientation & -0.04 & $-0.24 *$ \\
\hline Future safe & 0.06 & 0.10 \\
\hline Future honest & 0.12 & 0.09 \\
\hline Future friendly & 0.13 & 0.13 \\
\hline Future skilled & $0.24^{*}$ & 0.12 \\
\hline Future wealthy & $0.18^{*}$ & $0.25^{*}$ \\
\hline
\end{tabular}

The scores for each construct are coded from 1 to 5, 1 being the lowest score on the construct and 5 being the highest. $N=130 . * p<0.05$. 


\section{Figure legend}

Figure 1.: The three types of consistency assessed in our study. Mental models are cognitively consistent if the attitudes that reflect or motivate people's understanding of how the system works today and their policy choices are the same as the attitudes that reflect or motivate their beliefs regarding the future state of the system as a result of their choices. Mental models are dynamically consistent if the beliefs regarding the future state of the system which would result from people's policy choices are compatible with their understanding of how the system works today. We assessed the dynamical consistency by comparing people's predictions with the outputs of a computational model whose inputs are people's understanding of how the system works today and their policy choices. Mental models are relationally consistent if the attitudes that reflect or motivate people's understanding of how the system works today and their policy choices do not contradict these understanding and choices.

Figure 2.: Visual summary of the correlations between cognitive constructs (left, blue plate) and i) model input Parameters (top panel, 'System understanding') and ii) model Predictions (bottom panel, 'Prediction'). Blue and black links represent positive and negative significant correlations ( $\mathrm{p}<0.05)$, respectively, and link thickness maps correlation strength. RWA: Right-Wing Authoritarianism; SDO: Social Dominance Orientation; CFC: Consideration of Future consequences; Critical temp: Critical temperature.

\section{Appendix A: Specification of the relationships of the computational model}

The computational model is not aimed at describing accurately the climate change phenomenon. Instead, it has been designed to represent people's dynamic mental models of this issue. This model is a simplification of (Grigg, Boschetti et al. 2011, Boschetti 2012) and is based on several observations.

The computational model uses Euler integration to solve the following differential equations:

$$
\begin{aligned}
& \frac{\mathrm{d} P}{\mathrm{~d} t}=P\left[k_{\text {birth }}(P, A)-k_{\text {death }}(P, A)\right][1-P / K] \\
& \frac{\mathrm{d} A}{\mathrm{~d} t}=\left[k_{\text {growthCap }}+k_{\text {growthLab }} \frac{1}{P} \frac{\mathrm{d} P}{\mathrm{~d} t}-M_{\text {Cost }}-k_{\text {damage }}(W)\right] A
\end{aligned}
$$




$$
\frac{\mathrm{d} Q}{\mathrm{~d} t}=c(t) k_{\text {energy }}(A, P) P
$$

$$
W(\mathrm{Q})=\frac{\lambda}{1-\frac{5.35 \lambda \gamma}{C 0+A Q}}\left[5.35 \ln \left(1+\frac{A i r B \cdot Q}{C 0}\right)\right]
$$

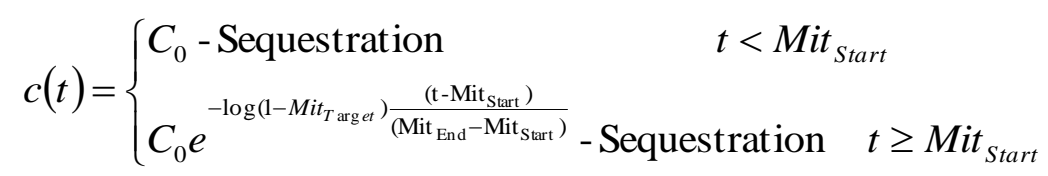

$\mathrm{A}, \mathrm{P}$, and $\mathrm{W}$ are respectively global economic activity, global population, and global warming; $k_{\text {birth }}, k_{\text {death }}$ and $k_{\text {energy }}$ represent birth, death and energy use rates as a function of GDP per capita, as estimated from UN data sets (http://unstats.un.org and http://data.un.org) over the 19702008 period (Grigg, Boschetti et al. 2011, Boschetti 2012); K is the Human Carrying Capacity; $k_{\text {growthCap }}$ is the economic growth due to capital and financial accumulation, and $k_{\text {growthLab }}$ is the economic growth due to labor growth (Grigg, Boschetti et al. 2011, Boschetti 2012).

Equation 4 relates cumulative $\mathrm{CO}_{2}$ emissions since $1751(Q)$ to peak temperature, which is used as an approximation of warming E (Raupach, Canadell et al. 2011). Here, $C O$ is the preindustrial mass of atmospheric $\mathrm{CO}_{2}(=596.4 \mathrm{PgC})$; $\mathrm{AirB}$ is the cumulative airborne fraction of $\mathrm{CO}_{2}$ in the absence of climate feedback on the carbon cycle (=.294), $\lambda$ is the Climate Sensitivity, and $\gamma$ is the aggregate sensitivity of all land and ocean carbon pools to climate change $(=40 \mathrm{PgC}$ $\left.\mathrm{K}^{-1}\right)$

Equation 5 defines the carbon density of energy use c(t) (Grigg, Boschetti et al. 2011, Boschetti 2012), which implements the climate mitigation measures. Here $C_{0}$ is the initial carbon intensity per unit energy (set to $20 \mathrm{~g}$ Carbon/MJ see (Raupach, Marland et al. 2007)), Sequestration 
is the natural sequestration, which is fixed at $10 \%$ of $C_{0}$ (Raupach, Marland et al. 2007), Mitstart is the year when mitigation initiatives start to take place (2015) and Mit $t_{\text {End }}$ is the year when the planned mitigation target $\left(\right.$ Mit $\left._{\text {Target }}\right)$ is reached.

$k_{\text {damage }}$ represents climate damages to the economy. We assume no damage occurs until the

Critical Temperature $\Delta T_{\text {Crit }}$ is reached; past that value, we have $k_{\text {damage }}=\min \left\{1, e^{r_{\text {dam }}\left(E-\Delta T_{\text {Crit }}\right)}-1\right\}$. Here we chose $r_{\mathrm{dam}}=0.0693 \mathrm{~K}^{-1}$ which leads to a full economic collapse only for a warming larger than $\Delta T_{C r i t}+10$ degrees, far exceeding most current predictions. It is important for the model to specify a critical temperature change beyond which normal human social systems will collapse. Somewhat arbitrarily, but not unreasonably, we selected +10 degrees.

\section{Appendix B: Model runs}

In addition to the parameterisations selected by the respondents, we sampled the computational model space defined in Table 1 exhaustively, in order to explore the full potential range of long-term system responses. Fig.B. 1 shows the state of the system in the year 2100, projected over the AW plane (Global Economic Activity vs. Global Warming). The model runs initialised with the respondents' parameterisation are shown as red dots, while the full set of exhaustive runs is shown as grey dots. 


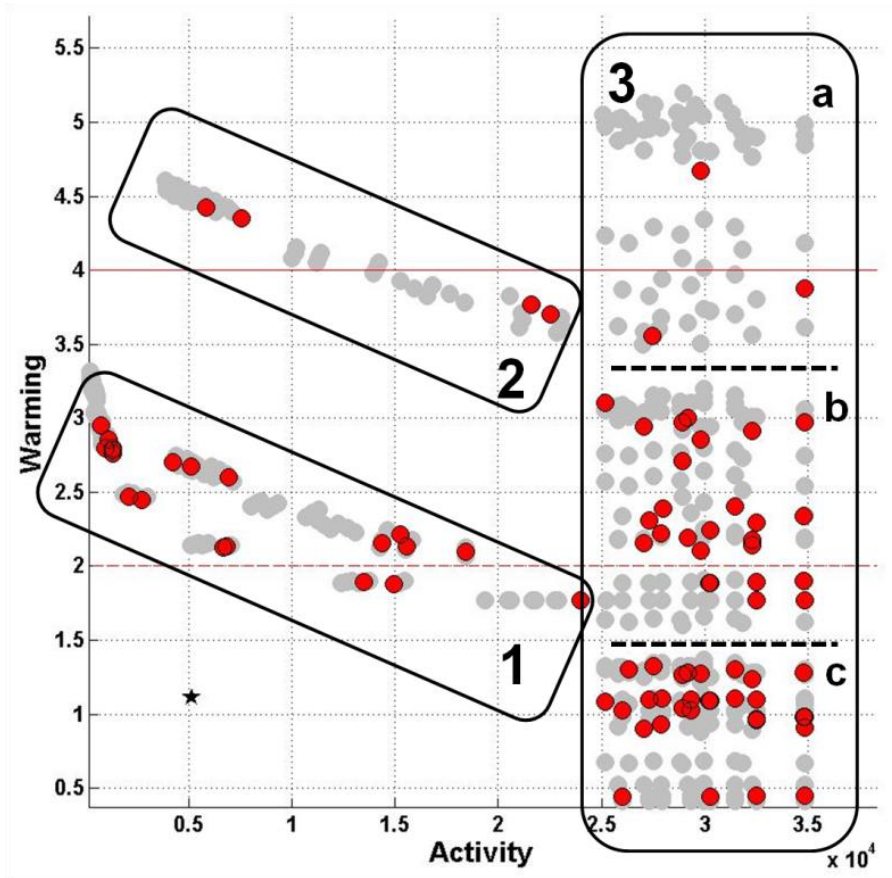

Fig.B. 1: Computational model output for year 2100. The original 3D output is projected over the AW (Economic Activity vs Warming) plane. Grey dots show all combinations of the input model parameters. Among these, the red dots show the model output for the respondents' choices. The black star marks the initial conditions (year 2005). The dashed and thick red horizontal lines define the $2^{\circ} \mathrm{C}$ and $4^{\circ} \mathrm{C}$ temperature increase, which are commonly recognised as the threshold of dangerous and extreme global warming, respectively (New, Liverman et al. 2011). The relation between the model parameters and the clusters $(1,2$ and $3 a, b, c)$ is described below.

We identify three regions in the output model space shown in Fig.B. 1, which are pertinent to the respondents' predictions 9 .

1) Region 1 represents the climate impact on economic activity when the Critical Temperature is $1.7^{\circ} \mathrm{C}$ and warming exceeds it. It is characterised by a clear negative correlation between warming and economic activity. In this region, different choices of mitigation policies and different values of climate sensitivity have a considerable impact on warming and as a result, an even larger impact on economic activity, which can vary between a richer and poorer future. The

\footnotetext{
${ }^{9}$ In order to better interpret Fig.B.1 it is useful to point out that sensitivity analysis (not included) shows that the model results are mostly controlled by 3 parameters: Mitigation Target, Climate Sensitivity and Critical Temperature, and to a lesser extent by Mitigation Cost. Mitigation Timeline and Human Carrying Capacity have a less significant impact.
} 
Author-produced version of the article published in Sustainability Science, 2017, N ${ }^{\circ} 12(1)$, p. 45-64.

negative feedback between these two variables prevents reaching the $4^{\circ} \mathrm{C}$ extreme warming threshold, because significant damage to the economic activity is already imposed at relatively low temperatures.

2) Region 2 shows similar behaviour to case 1 , but for a Critical Temperature of $3.3^{\circ} \mathrm{C}$. In this case the model output lies around the $4^{\circ} \mathrm{C}$ extreme warming (marked by a red reference line in Fig.B. 1) and occasionally exceeds it.

3) In Region 3 warming does not affect economic activity. This occurs because warming does not exceed either a Critical Temperature of $1.7^{\circ} \mathrm{C}$ (Region $\left.3 \mathrm{c}\right), 3.3^{\circ} \mathrm{C}(3 \mathrm{~b}-\mathrm{c})$ or $5^{\circ} \mathrm{C}(3 \mathrm{a}-\mathrm{c})$. This region is characterised by wide variability in warming as a function of mitigation policies and climate sensitivity. However, these do not impact economic activity, which is affected only by mitigation cost and population size. Because mitigation cost affects GDP growth less than climate damage, this region is characterised by a future considerably richer than today.

\section{Appendix C: Model description to respondents}

Consider a global system made up of three variables: $i$ ) global economy (represented by the global Growth Domestic Product (GDP) per person. As the global GDP per person is the value of all the goods and services produced in the world divided by the number of people, it indicates the strength of the economic activity), ii) the size of the global population $(P)$ and iii) the state of the climate (E, for the environment, represented by the global temperature rise).

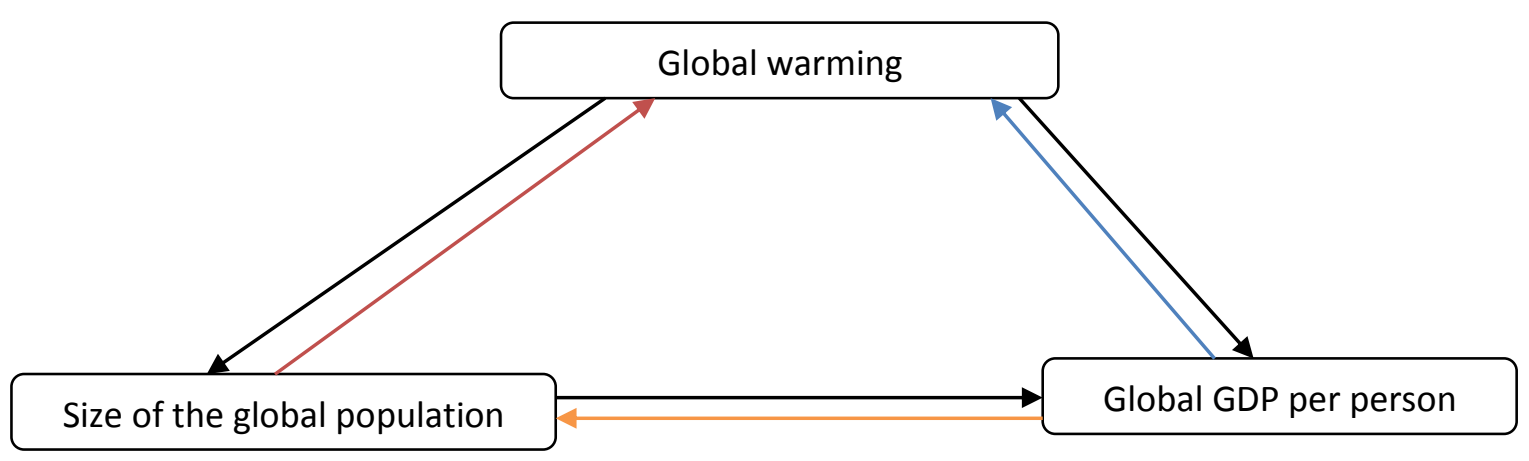


Author-produced version of the article published in Sustainability Science, 2017, $N^{\circ} 12(1)$, p. 45-64.

Fig.C. 1: Model description

Then, the respondents were presented with three stable relationships that affect the variables:

Impact of the global economy on Population:

-When GDP per person increases, the birth rate decreases. It is empirically shown (at least in developed countries) that the wealthier people become the less children they have. This in turns may lead to population decline.

\section{Impact of Activity on Environment:}

- When GDP per person increases, energy use per capita increases. As a result, the amount of $\mathrm{CO}_{2}$ in the atmosphere increases.

Impact of Population on Environment:

- When the global population increases, the amount of $\mathrm{CO}_{2}$ in the atmosphere increases.

Finally, the respondents were presented with a description of each of the parameters listed in Table 1 and were asked to assign them one of the value chosen amongst the possibilities proposed in Table 1:

\section{Relationships affected by beliefs}

1. Maximum number of people who could live on the Earth (Earth carrying capacity):

We all know the Earth is finite in size and resources. Thus, it can't support an infinite number of human beings. In your opinion, what is the maximum number of people who could live on the Earth? (In 2012, there are approximately 7 billion people in the World).
15 billon
$\square 27$ billion
40 billion 
Author-produced version of the article published in Sustainability Science, 2017, N 12(1), p. 45-64.

\section{Critical temperature:}

We believe that if the global warming reaches a certain value (the "critical temperature value") the human activity will be affected and the GDP per capita will decrease. However, scientists don't agree on the value of this critical temperature.

- $\quad$ The most optimistic believe that we won't see any effect on the economy until the global warming reaches $5^{\circ} \mathrm{C}$.

- The most pessimistic believe that climate change will start to affect the economy from an increase in the global temperature of $1.7^{\circ} \mathrm{C}$.

In your opinion, what statement is the most likely?

Climate change will start to affect the economy from a global warming of:
$1.7^{\circ} \mathrm{C}$

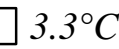
$\square 5^{\circ} \mathrm{C}$

3. Climate sensitivity:

Scientists don't agree on how much the rise of $\mathrm{CO} 2$ in the atmosphere affects the global temperature.

- The most optimistic believe that if the amount of $\mathrm{CO} 2$ in the atmosphere doubled, the rise in global temperature would be $1^{\circ} \mathrm{C}$.

- The most pessimistic believe that if the amount of $\mathrm{CO} 2$ in the atmosphere doubled, the rise in global temperature would be $3.4^{\circ} \mathrm{C}$. 
Author-produced version of the article published in Sustainability Science, 2017, N ${ }^{\circ} 12(1)$, p. 45-64.

The original publication is available at https://link.springer.com

Doi: 10.1007/s11625-016-0384-2

Mental models of climate change

In your opinion, if the amount of $\mathrm{CO} 2$ in the atmosphere doubled, the rise on global temperature would be:
$\square 1^{\circ} \mathrm{C}$ (weak sensitivity)
$\square 2.2^{\circ} \mathrm{C}$ (mild sensitivity)
$\square 3.4^{\circ} \mathrm{C}$ (strong

sensitivity)

\section{Relationships affected by opinions}

According to your beliefs regarding the parameters above, give your opinion about the following policies:

1. We should reduce the human global emissions of CO2 by:

$\square$ There is no need to reduce our emissions (go to the "Predictions" subsection)

$5 \%$

$45 \%$

$90 \%$

2. $90 \%$ of the goal chosen above should be achieved by:

$\square 2020$

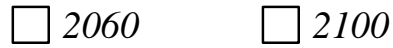

3. If we manage to reach the goal you chose, how much do you think it will cost:

$\square 0 \%$ of the GDP $\square 10 \%$ of the GDP $\square 20 \%$ of the GDP 